\title{
How Does Population Aging Influence Political Polarization
}

\author{
Shuang Yu, Xiaojun Zhao \\ School of Economics, Peking University, Beijing, China \\ Email address: \\ yushuang1995@126.com (Shuang Yu), zhaoxiaojun@pku.edu.cn (Xiaojun Zhao)
}

To cite this article:

Shuang Yu, Xiaojun Zhao. How Does Population Aging Influence Political Polarization. Psychology and Behavioral Sciences. Vol. 10, No. 4, 2021, pp. 145-159. doi: 10.11648/j.pbs.20211004.14

Received: July 14, 2021; Accepted: July 23, 2021; Published: August 31, 2021

\begin{abstract}
The population aging has been considered as a major trend in China. By 2019, people aged 60 or older has exceeded $2.49 \mathrm{~m}$, accounting for $17.9 \%$ of the population, while people aged 65 or older has reaches $1.76 \mathrm{~m}$, accounting for $12.6 \%$ of the population. However, there were no clear empirical evidences that show how political polarization is affected by the older population. We use a four-round household data from 2012-2018 CFPS of China to construct a large panel data including 14,352 adults each year. This paper computes the polarization index of eight typical public events and combines them to construct an overall index, using Gini coefficient, Theil index, and Atkinson index. We find that the index is larger for the oldest than for the youngest group in overall and eight measures, indicating that political polarization has gradually bifurcated with age. To explain this phenomenon, we focus on the demographic differences in information channel, parental influence, occupation distribution and regional migration between young and old people as evidence of higher polarization. Then, a Tobit model estimated at the age-province level implies that increase in average age is associated with significant grows in polarization index and four channel effects also hold. These findings provide a new perspective to explain the reason for increasing political polarization.
\end{abstract}

Keywords: Public Events, Political Polarization, Population Aging, China

\section{Introduction}

The aging population is an important trend of social development, and also the basic condition of China for a long period of time in the future $[9,10,13,15]$. Since China entered the aging society at the end of the 20th century, quantities and proportions of aging populations have continued to increase. By 2019, people aged 60 or older has exceeded $2.49 \mathrm{~m}$, accounting for $17.9 \%$ of the population, while people aged 65 or older has reaches $1.76 \mathrm{~m}$, accounting for $12.6 \%$ of the population (World Health Organization). The aging population is still rising, which is estimated to reach $4.8 \mathrm{~m}$ by 2050. Compared with the census data from 1953 to 2010, the characteristics of population's age composition mainly show that the structure changes from a typical positive "pyramid" to a non-"pyramid" structure (seen from Figure 4), and the population cohort is neither steadily increasing nor stable decreasing, showing the trend of ups and downs. Under the current economic situation, the problem of population aging and its changes in the population age structure have aroused great concern in the society, and the consequences caused by the aggravation of aging population are becoming increasingly important.

This worldwide change in demographics of human populations is linked to unanticipated and unprecedented economic, cultural, medical, social, public health and public policy challenges $[3,8,12,14]$. Many studies suggest that the society should pay more attention to the health and living conditions of the elderly, like building age-friendly community [7], improving medical pricing [5], and decreasing social detachment [6]. From the aspect of labor supply, Dall [4] found that the big demand for health care services requires a large health care workforce by 2025. On the other hand, Choi and Shin [2] argued that population aging causes a decrease in labor supply growth and an increase in capital stock growth, undermining growth potential. Because the population aging causes the above-mentioned various social problems, this article believes that aging also brings about changes in the public views on these social issues. It is necessary for this article to analyze the demographic characteristics of these public views, and this kind of research on social viewpoints has important practical significance for the formulation of government policies and the maintenance of social stability.

Some authors use domestic data to analyze the characteristics of specific public view. Sabater [11] used 
census data from England and Wales to conclude that geographical separation between older and younger groups is higher with increasing age. With further analysis, Boxell [1] found that the oldest age group experiences larger changes in polarization than the youngest age group. These studies only describe the phenomenon of higher political polarization among the elderly, but do not deeply explain the reasons and analyze the mechanisms. Based on this, this article focuses on how population aging influences the view of public event.

In this work, we use survey data to study how trends in public event polarization relate to population aging. Using data from China Family Panel Studies (CFPS), we choose Gini index, Theil index and Atkinson index to compute eight measures of political polarization that is of great concern in recent years, including education issue, medical issue, housing problem and so on. Instead of analyzing polarization trend and how to decrease polarization index, we start with the measures of polarization in each age group and try to analyze the situation in four demographic differences.

We show, using data from CFPS, that a Gini index of our eight polarization measures is 0.166 overall between 2012 and 2018. The figure is $0.133,0.168$, and 0.192 , respectively, among those aged 16-39, 40-64 and 65+. The absolute value is larger for the oldest than for the youngest group in all eight measures, indicating that the public view of social events has gradually bifurcated with age.

In order to explain the reasons for this phenomenon, we study the demographic differences in information channel, parental influence, occupation distribution and regional migration between young and old people as evidence of higher polarization. In terms of information channel, young people are mainly affected by social networks, while most of the elderly use traditional social media to understand public events. Because the segmentation effect of traditional channel is much greater than that of social media, the elderly have the higher polarization index of public event. Under the influence of parents, young people have less influence from the family than the middle-aged people, partly explaining the age characters of polarization index. Furthermore, individuals join in specific business groups under the influence of social networks with experience, such as doctor, teacher, etc. While the decentralized characteristic between different occupations causes the Gini coefficient to increase further. Moreover, due to factors such as employment and school attendance, young people move between multiple provinces for a short period of time, and it is difficult to suffer from the long-term influence of regional characteristics on individual perceptions. Individuals are employed and settled in specific provinces with age, and then affected by differences of each province.

We contribute to the literature by documenting how population aging affects the polarization of public events and by using four different channels to explain the formation of the views among the elderly.

\section{Data Source and Descriptive Analysis}

The data comes from multiple sources. Polarization of public events is extracted from China Family Panel Studies (CFPS) conducted by Institute of Social Science Survey (ISSS). In the year of 2012, 2014, 2016 and 2018 four rounds of nationwide household surveys were carried out. The target sample of CFPS consists of 16,000 households in 25 provinces/municipalities/autonomous regions in China (excluding Hong Kong, Macao, Taiwan, Xinjiang, Tibet, Qinghai, Inner Mongolia, Ningxia and Hainan). All eligible households and household members are subjects of the survey. By collecting data at three levels (individual, family, community) in which the individual level is classified by age (adult and children), the project aims to document changes in Chinese society, economy, population, education, and health, so as to provide data for academic research and public policy analysis.

\subsection{Trends in Age}

Panel A and Panel B of Figure 5 reflect life expectancy in China and the world. In general, the life expectancy of men, women, and the whole has gradually increased with the year and life expectancy for women continues to be five years longer than for men. Meanwhile, China has higher life expectancy than the global, averaged by about 5 years, indicating that the overall life expectancy has been greatly extended due to the improvement in medical conditions, living conditions and economic conditions. Panel $\mathrm{C}$ and Panel D are based on the proportion of people age 65 years and older, reflecting the aging situation in China and the world. In summary, the aging situation of men, women and the whole is gradually intensifying and the aging level of women is still about $2 \%$ higher than that of men. Especially for China, the aging situation is similar to the world before 2012, but then showing a sharp upward trend. The overall level of China has reached $10.96 \%$ in 2018 , which is about $2 \%$ higher than the average condition of the world $(8.87 \%)$. As can be seen from the figure above, the aging has become the worldwide basic social phenomenon and has also shown a rapid increase in China in recent years. The increase in the elderly has a serious impact on medical problems, labor supply, social security, etc., as well as the change in public opinion. Then, we specifically study the impact of aging on the public event polarization.

\subsection{Measure of Public Event Polarization}

Public events are covered in the CFPS adult's questionnaire. A set of eight questions is designed to measure the severity of public events, including environmental issue, education issue, employment issue, wealth gap, social security, medical issue, government corruption and housing problem. Respondents need to choose from ten items (0-10) according to the true situation, value 0 represents "not serious" while value 10 represents "very serious". If respondent believes that such problems are serious in China, he can pick higher numbers. These items only examine the severity of individual's perception of public events, but do not reflect the distribution characteristics of the public opinion. Therefore, this article uses the Gini coefficient, Theil index, and Atkinson index to 
examine the polarization degree of public events. The smaller value represents the concentrated view of the majority, while the larger value explains more diffuse of common view. The formula of three index is as follows

Gini coefficient:

$$
\mathrm{G}=\sum_{i=1}^{N} x_{i} y_{i}+2 \sum_{i=1}^{N} x_{i}\left(1-v_{i}\right)-1
$$

Among them, $x$ represents the proportion of population in each group, $y$ represents the proportion of the severity of public events in each group, $\mathrm{v}$ represents the cumulative proportion of income in each group, $\mathrm{n}$ represents the number of groups of groups.

Theil Index:

$$
\mathrm{T}=\sum_{i=1}^{N}\left(\frac{x_{i}}{\sum_{j=1}^{N} x_{j}} * \ln \frac{x_{i}}{\bar{x}}\right)
$$

Where $x_{i}$ is the severity of public events of $\mathrm{i}$-th person, $\bar{x}$ is the average severity, and $\mathrm{N}$ is the number of population. The first term in the totalization symbol can be understood as the proportion of an individual's total public events index, and the second term is the individual's perception of public events relative to the mean.

Atkinson index:

As for the function of Atkinson index, $T_{i}$ is the public events index in the ith index range, $f_{i}$ is the proportion of the population in the ith group. $\bar{T}$ is the mean public events index, and the Atkinson equation are defined as follows:

$$
\begin{gathered}
y_{R}=1-\left[\sum_{i=1}^{n} \frac{T_{i}{ }^{1-\varepsilon}}{\bar{T}} f_{i}\left(T_{i}\right)\right]^{\frac{1}{1-\varepsilon}}, \text { if } \varepsilon \neq 1 \\
y_{R}=1-\exp \left[\sum_{i=1}^{n} f_{i}\left(T_{i}\right) \log _{e} \frac{T_{i}}{\bar{T}}\right], \text { if } \varepsilon=1
\end{gathered}
$$

As the equation shows, the Atkinson index evaluates the distributional effect of public events index with the epsilon parameter.

Figure 1 plots each of these polarization measures, including the index, over time. By design, all of the measures we include show an overall decrease in polarization, which explains that the public view of China's events shows a gradual gathering trend. Among them, the Gini coefficient of education issues, social security, medical issues and housing issues is relatively large, with the index decreasing by $0.3-0.5$ index points between 2012 and 2018. This distribution characteristics indicate that the public has greater disagreement on these four types of issues, while on other issues the view is more concentrated.
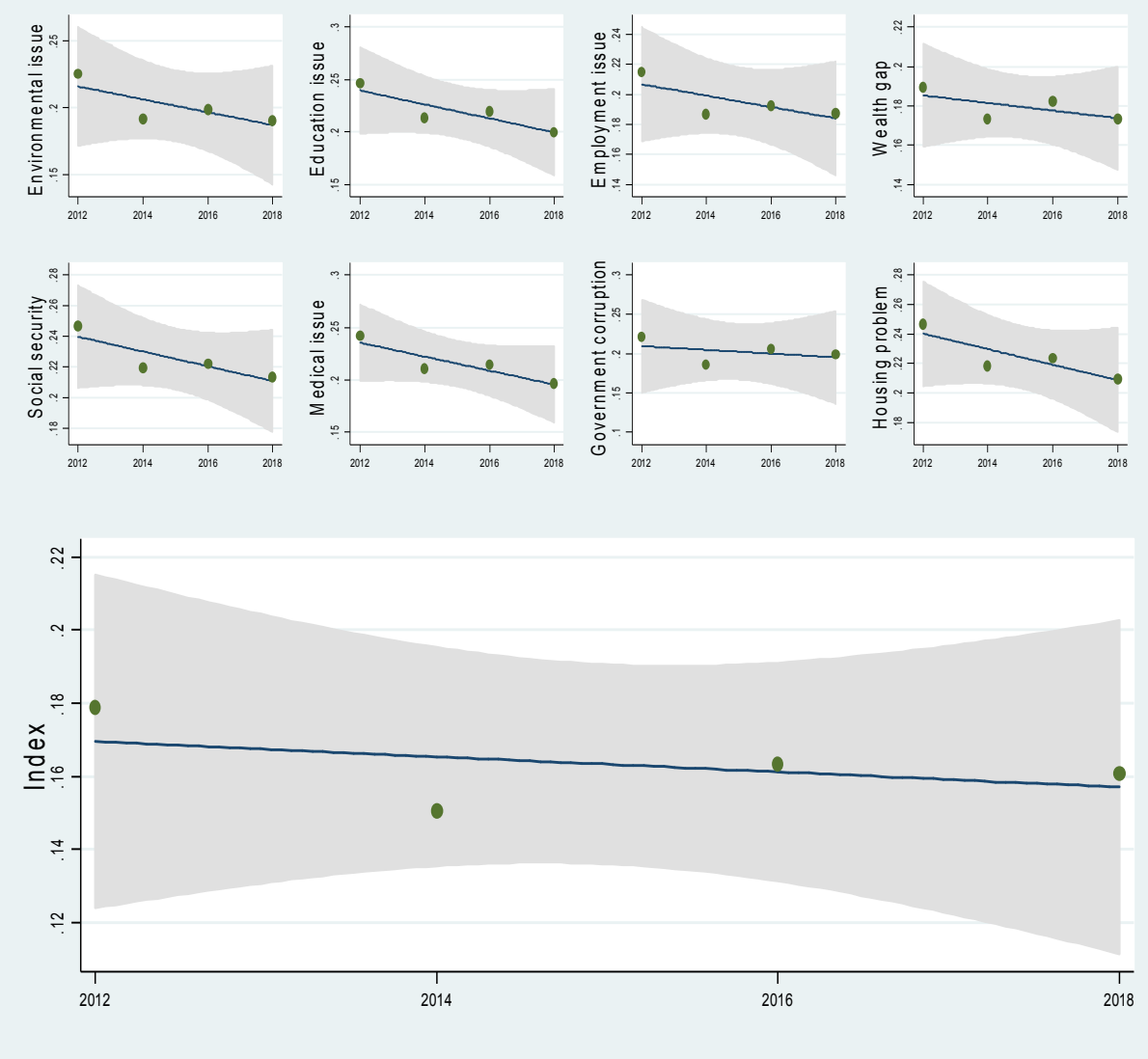

Figure 1. Trends in Polarization of Public Events.

Notes: Each of the eight small plots shows the trend in a Gini coefficient across time. The large plot shows the trend in the index, which is computed as the average across all polarization measures available in a given year. The shaded regions are 95 percent confidence intervals constructed using a nonparametric bootstrap with 100 replicates. 


\subsection{Trends in Polarization by Demographic Group}

\subsubsection{By Age Group}

Figure 2 below shows the polarization index of public events by age, which indicates that the polarization degree of public events in various age groups is clearly stratified. The Gini coefficient of the elderly aged $65+$ is the largest figure among three age groups and continuously increases with time, between 0.18 and 0.2 . For middle-aged people, the index reduces to 0.16-0.17 and shows a slight decrease with time. Young people have the lowest degree of polarization (only 0.13-0.14), which remained unchanged after a slight increase before 2016. This phenomenon indicates that the public view of social events has gradually bifurcated with age.

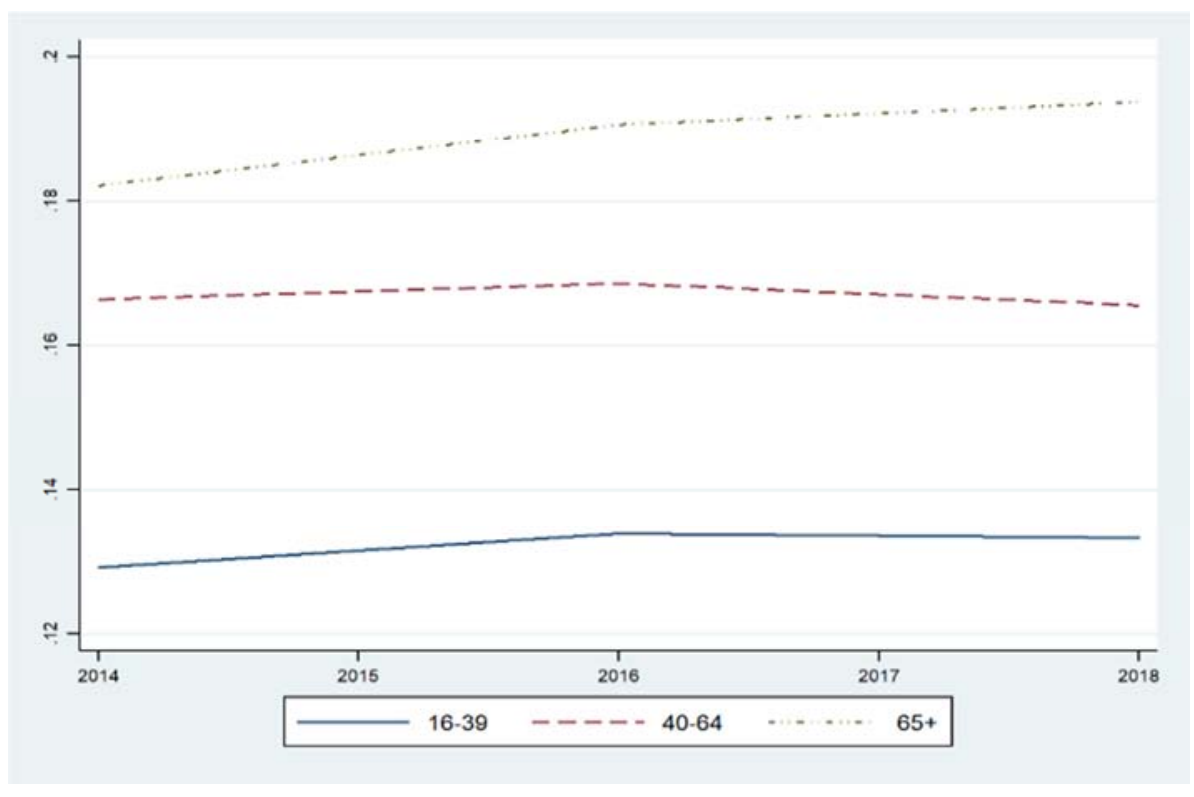

Figure 2. Trends in Polarization by Age Group.

Notes: Figure shows the polarization index broken out by age group. For a given measure and group, the polarization value is calculated into Gini coefficient in the full sample. The index is the weighted average of these normalized polarization measures for each group.

Table 1 provides additional quantitative detail. Between 2012 and 2018 , polarization grew by $0.133,0.168$ and 0.192 index points, respectively, among those aged 16-39, 40-64, and $65+$. Specifically, the most differentiated view between the elderly and the young is in terms of environmental issues and social security, reaching more than 0.06 , while the difference in employment issue and wealth gap is relatively small, less than 0.05. In order to further investigate the distribution characteristics of each age group, this paper then describes the frequency histogram of each age group.

Table 1. Growth in Polarization 2012 to 2018.

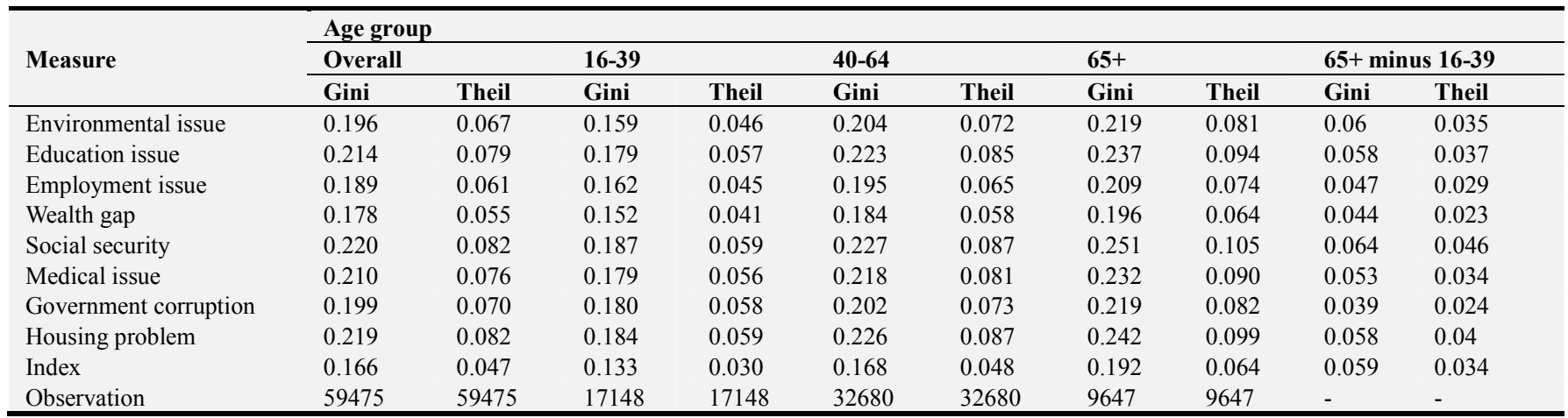

Notes: Table shows the change in each measure, and in the index, from 1996 to 2012 . The "Overall" column includes all ages. Columns "16-39", "40-64" and "65+" re-calculate the measure in Gini coefficient and Theil index for each age group. The last two columns show the difference in growth between the two age groups. Standard errors are in parentheses and are constructed using a nonparametric bootstrap with 100 replicates.

From the perspective of age distribution in Figure 3, public opinions of young people aged between 16 and 39 have the highest degree of centralization. The cognitive severity of public event is mainly concentrated between 6-7 and 7-8 (with 21.6 and 21.38 percent, respectively), while the cumulative percentage under 5 is only $12.41 \%$. The centralization degree 
of opinion among middle-aged people gradually disperses, and the cognitive severity generally reduces. It mainly centralizes in 5-6 and 6-7 (with 21.42 and 21.12 percent, respectively), while the cumulative percentage below 5 has increased to $23.92 \%$. The extreme view of $8-9$ and $9-10$ have decreased from $16.45 \%, 11.75 \%$ to $10.65 \%$ and $6.77 \%$. For the elderly over 65 years, the concentration of opinions is further dispersed, with a significant peak of $23.94 \%$ between 5-6. And the image shows a trend similar to normal distribution, for which the cumulative percentage below 5 rises to $32.55 \%$, while the cumulative percentage above 6 decreases to $43.51 \%$.

The original unified view further diverges with age, showing a smoother distribution trend. The Gini coefficient continues to increase, while the perspective severity of public event generally declines. It may be because of the following three reasons: First, young people are mainly affected by social networks, while most of the elderly use newspapers, radio, television and other traditional social media as information channel to understand public events. Traditional channel gradually exacerbates the influence of personal views with age. Because of the fragmentation on public views, it increases the degree of social inequality. Secondly, young people have not yet formed an independent view of events, mainly affected by their teachers and parents. The concentration of teachers' view further strengthens to increase the concentration of young people's views. Furthermore, individuals join in specific groups under the influence of social networks with experience, such as occupations, regions, etc. Each group shares data among its members, and then form a unified tendency of thinking within group. While the decentralized characteristic between various groups causes the Gini coefficient to increase further. This article explains these three channels of influence separately.

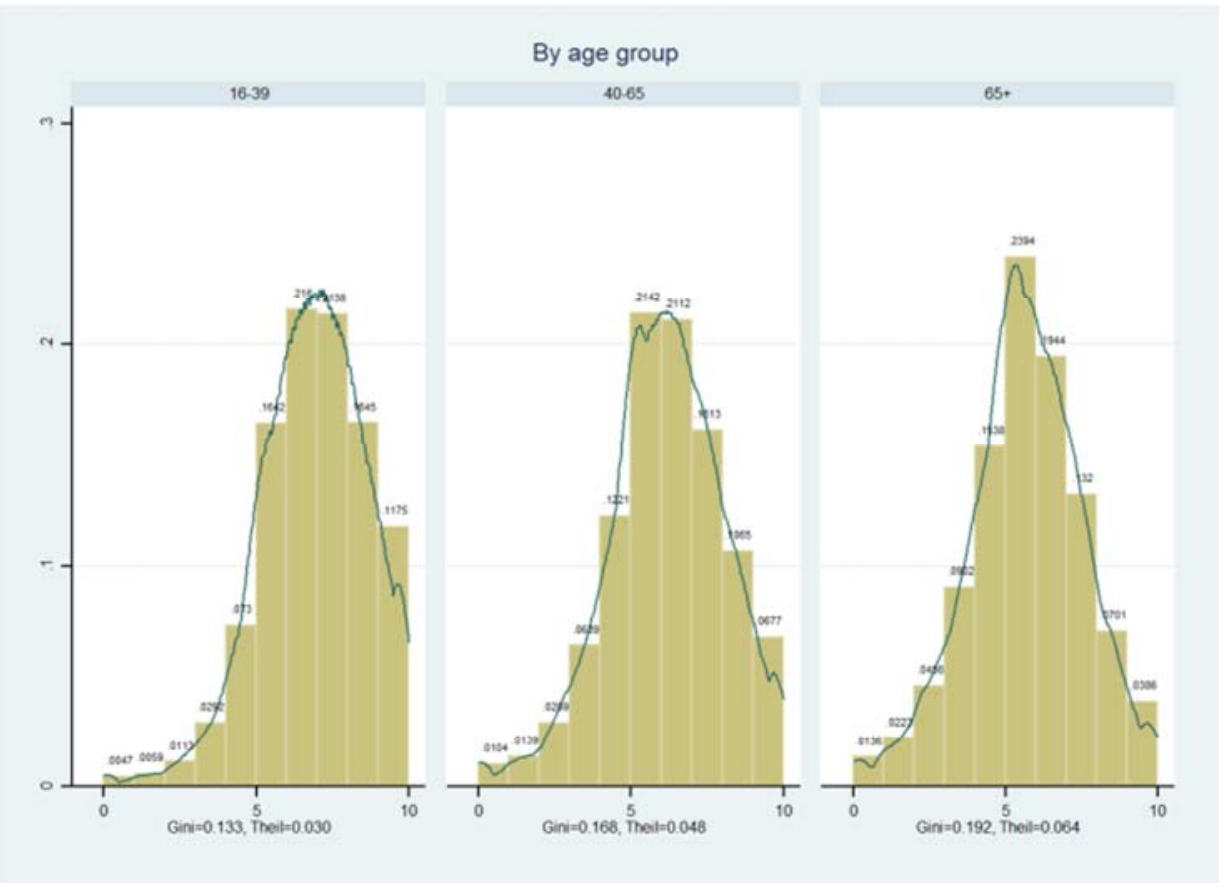

Notes: Each plot shows the distribution characteristics of polarization index by age group. The black line is the kernel density curve.

Figure 3. Frequency Distribution Histogram of Polarization Index by Age Group.

\subsubsection{By Information Channel}

Figure 6 describes the information statistical indicators by age. It can be seen from Figure that there is the highest percentage of political speeches posted on the website for people aged between 40 and 64, remaining between $17 \%$ and $19 \%$. The proportion of young people ranks only second to middle-aged people and shows a slight downward trend between 2014 and 2018. The percentage of the elderly is the lowest one in three groups but has increased significantly over time, from $4 \%$ to $7 \%$ and gradually reach to the proportion of young people. The change tendency in Panel B is basically the same as that in Panel A, showing that the substantial increase in the proportion of old people making political speeches through the website may be related to the increase in Internet penetration. From Panel C and Panel D, the elderly mainly uses TV to understand political information, while the young mainly use the Internet to understand political information, which is in line with our expectations.

In order to know the influence of information channels on the polarization of public events, Figure 7 depicts the polarization level of political information learned through television and the Internet. It can be seen that high usage of $\mathrm{TV}$ and the Internet to understand politics has the positive correlation with the polarization index, indicating that traditional media and social media both have a segmentation effect of public opinions. However, the segmentation effect of TV channels is much greater than that of social media, with the Gini coefficient increasing from 0.15 to 0.17 , while the Gini coefficient of the Internet channel only rises from 0.11 to 
0.13. The possible explanation is that the traditional media tends to promote a unified point of view, which brings about a dual effect of society. Some people believe in public reports, but others hold opposite attitudes, thus forming a confrontation between two opinions and aggravating the divergence of social opinions. On the other hand, the Internet spreads opinions through directional push, group effect, and random forwarding, which is fragmented and be difficult to form a continuous attention in people's minds. But it also slightly increases the differentiation of social opinions. According to the previous discussion, the elderly mainly understands the political information through television, while the young usually disseminates information through the Internet. The information segmentation effect of traditional channels promotes the polarization index of the elderly to be greater than that of the young people.

\subsubsection{By Parental Influence}

This paper further analyzes the cause of polarization indicators in various ages from the influence of parents on children. It can be seen from the Figure 8 that people aged between 16-39 and 40-64 are more affected by parents, while older people over 65 are less affected by parents, and the effect of father on children is greater than mother's effect. From the analysis in the figure, it is known that the public polarization indicators continue to increase with age. The parents of young people are mainly in the middle age, while the parents of middle-aged people are mainly in the old age. Therefore, under the influence of parents, the polarization index of young people is smaller than that of middle-aged people. Meanwhile, the polarization index of the elderly remains at a higher level even if it is less affected by their parents, because the index is still higher. Based on this analysis, under the influence of parents, polarization index continues to increase with age.

\subsubsection{By Business Group}

As shown in the Figure 9, among 6 industrial divisions, working as teachers, financial practitioners, and administrative officers has lower Gini coefficients and a higher centralization degree of opinions. Specifically, teachers' opinions are mainly concentrated between 6-8, accounting for about $45.86 \%$, with high severity $8-10$ accounted for $25.9 \%$. The distribution of opinion in the financial industry has similar characteristics as the education industry distribution. The percentage of views between 6 and 8 accounts for $45.47 \%$, but the proportion of particularly serious view increases to $29.05 \%$. Moreover, the opinion of administrative officers is further divided, still concentrating between 6 and 8 , but the proportion drops to $42.29 \%$.

For the other three categories, the Gini coefficient of physicians, self-employers and unemployed is relatively high. There is a single peak between 6 and 7 in the medical industry, accounting for about $22.85 \%$. The proportion of the number which is higher than 7 is $44.05 \%$, while the proportion of value lower than 6 is $33.15 \%$, showing a gradual differentiation trend. The trend of unemployed distribution is similar to that of medical staff, existing a peak value between 6 and 7. But the proportion of values below 6 increases to
$41.08 \%$. The Gini coefficient of self-employer is the highest among six professions, indicating that their opinions are the most dispersed. Meanwhile, the cognitive severity generally declines, which is concentrated between 5 and 7, accounting for about $42.17 \%$. The percentage of particularly serious number marked 8-10 declines to $20.79 \%$.

It can be seen from the above statement that industries with unified rules and regulations, comprehensive management methods, and consistent goal pursuits (such as teaching, finance, and administrative agencies) have a high concentration of opinions, because it is easier to form the trend of disseminating views and peer effect in these industries. However, self-employer and unemployed are not in a strict industry segmentation. Their lives and work are mainly based on their subjective wellbeing, so they are less affected by the same business members around them, making it difficult to form a coherent view in this industry. Furthermore, because there are huge differences in the processes, working modes, salary, and working hours of various industries, the views are only unified within each industry and gathered into a specific group. Besides, there can be serious divergence of views between industries. Hence, this occupational differentiation forms the overall polarization phenomenon of public view.

\subsubsection{By Region Group}

In order to investigate whether regional characteristics cause polarization of public event for the elderly, this paper measures the population migration status of each age group and the regional viewpoint polarization index of 25 provinces in China.

The following definition is creatively made in this paper to measure the frequency of population migration. If the individual is located in the same province as the next year, it means that the individual has not migrated, defining as 0 . If two adjacent years are located different provinces, we defined this figure as 1 , representing individuals who have carried out migration activities. Then we add three digits and obtain an index as migration frequency. Based on this definition of migration index, this article divides total age into six groups aged 16-29, 30-39, 40-49, 50-59, 60-64 and 65+ to measure the migration level in every age group. As can be seen from the Figure 10, the migration volume of individuals showed a significant downward trend with age. The migration volume in the 16-29 age group is 1.34 , while the elderly population aged over $65+$ only has a migration volume of 0.12 . Due to factors such as employment and school attendance, young people move between multiple provinces for a short period of time, and it is difficult to suffer from the long-term influence of regional characteristics on individual perceptions. Individuals are employed and settled in specific provinces with age, then affected by differences of each provinces.

As can be seen from the Table 3 below, there is a clear difference in the polarization index of public views among these provinces. The index of Chongqing is the highest, reaching to 0.188 , while the index of Tianjin and Guangdong is within 0.15 , indicating that there are obvious differences in the perception of public events among provinces. Therefore, 
individuals join in specific groups under the influence of regional networks with experience. Each province shares data characteristics, and then form a unified thinking tendency within the province. Because of decentralization characteristics between provinces, the Gini coefficient of middle-aged and elderly people has further increased. Figure 11 is the frequency histogram of the distribution of public opinion on social events in various provinces.

\section{Empirical Analysis}

We first report estimated results of average age on polarization index. Moreover, we consider heterogeneous responses by information channel, parental influence and occupation distribution. Because each polarization index is a limited number, we use a Tobit model to do all the regressions. All standard errors are robust and control for province-year fixed effects.

\subsection{Empirical Model}

We estimate the influence of population aging on polarization index in the following model:

$$
P I_{\text {ipt }}=\alpha_{p t}+\beta A g e_{p t}+\gamma X_{p t}+\delta_{p t}
$$

where, the dependent variable $\mathrm{PI}_{\mathrm{ipt}}(\mathrm{i}=1,2,3)$ is the three measures of polarization index of province $p$ in year $t$. Age $_{\mathrm{pt}}$ is the average age of $p$ province in year $t . \alpha_{\mathrm{pt}}$ is province-year fixed effects, which could reflect the time trend of specific province that affects both population aging and polarization index. $\mathrm{X}_{\mathrm{pt}}$ includes province characteristics which potentially affect the distribution of public views by each province, including average education level, per capita GDP, urbanization level, proportion of public education expenditure, proportion of secondary industry, proportion of third industry, and import and export weight.

\subsection{Estimation Results}

\subsubsection{Results for Polarization Index}

Columns 1-10 of Table 2 reports the Tobit estimated response of the polarization index equations for the five measures. All specification control for year-province fixed effects, and other province level variables.

As in Table 2, increases in average age are associated with significant grows in polarization index. From the columns (2), (4), (6) and (8), the estimate on average age is positive and significant at the $1 \%$ level: for a 1 -year increase in average age, Theil index, Gini coefficient, 0.5 of Atkinson index and 1 of Atkinson index increase by $0.003,0.002,0.001$ and 0.002 , respectively. But when it is increased to 2 , the coefficient of Atkinson index decreases to 0.001 and is not significant. Our results for political polarization are in line with previous findings from developed countries that the oldest age group experienced larger polarization than the youngest age group (Starling, 2014; Boxell et al., 2017).

This finding is consistent with the above analysis that the view of public events further diverges with age. In terms of control variables, the increase in the proportion of public education investment significantly expands the polarization coefficient, indicating that the overall civic quality and education level increase with increase in education investment People have a higher degree of public events attention and form a personal opinion, bringing about a divergence of social perspectives. The increase in the secondary industry's share of GDP also significantly expands the polarization index, indicating that the development of industrialization stimulates the awakening and divergence of human consciousness.

Table 2. Regression Results for Alternative Measures of Polarization Index.

\begin{tabular}{|c|c|c|c|c|c|c|c|c|c|c|}
\hline & \multirow{2}{*}{$\begin{array}{l}\text { Theil } \\
(1)\end{array}$} & \multicolumn{3}{|c|}{ Gini } & \multicolumn{2}{|c|}{ Atkinsom (0.5) } & \multicolumn{2}{|c|}{ Atkinsom (1) } & \multicolumn{2}{|c|}{ Atkinsom (2) } \\
\hline & & (2) & (3) & (4) & $(5)$ & (6) & $(7)$ & (8) & (9) & (10) \\
\hline \multirow[t]{2}{*}{ Age } & $0.001 * *$ & $0.003 * * *$ & 0.001 & $0.002 * * *$ & 0.0003 & $0.001 * * *$ & 0.0005 & $0.002 * * *$ & -0.001 & 0.001 \\
\hline & $(0.001)$ & $(0.001)$ & $(0.0003)$ & $(0.0004)$ & $(0.0002)$ & $(0.0002)$ & $(0.0005)$ & $(0.001)$ & $(0.002)$ & $(0.002)$ \\
\hline \multirow[t]{2}{*}{ Edu_level } & & -0.011 & & -0.006 & & -0.003 & & -0.006 & & -0.005 \\
\hline & & $(0.008)$ & & $(0.005)$ & & $(0.003)$ & & $(0.006)$ & & $(0.024)$ \\
\hline \multirow{2}{*}{ lnGDP_per } & & 0.012 & & 0.006 & & 0.003 & & 0.006 & & -0.004 \\
\hline & & $(0.010)$ & & $(0.006)$ & & $(0.003)$ & & $(0.008)$ & & $(0.031)$ \\
\hline \multirow[t]{2}{*}{ Urban } & & -0.008 & & -0.001 & & $-7.95 e-05$ & & 0.0003 & & -0.035 \\
\hline & & $(0.036)$ & & $(0.022)$ & & $(0.013)$ & & $(0.030)$ & & $(0.113)$ \\
\hline \multirow[t]{2}{*}{ Edu_inv } & & $0.496 * * *$ & & $0.243 * *$ & & $0.116^{*}$ & & 0.196 & & -0.317 \\
\hline & & $(0.187)$ & & $(0.113)$ & & $(0.065)$ & & $(0.155)$ & & $(0.584)$ \\
\hline \multirow[t]{2}{*}{ Sec_ins } & & $0.104 *$ & & $0.057 *$ & & $0.031 *$ & & 0.071 & & 0.222 \\
\hline & & $(0.054)$ & & $(0.033)$ & & (0.019) & & $(0.045)$ & & $(0.169)$ \\
\hline \multirow[t]{2}{*}{ Thi_ins } & & 0.0318 & & 0.019 & & 0.012 & & 0.031 & & 0.175 \\
\hline & & $(0.064)$ & & $(0.039)$ & & $(0.022)$ & & $(0.053)$ & & $(0.200)$ \\
\hline \multirow[t]{2}{*}{ Trade } & & -0.014 & & -0.008 & & -0.005 & & -0.011 & & -0.031 \\
\hline & & $(0.008)$ & & $(0.005)$ & & $(0.003)$ & & $(0.007)$ & & $(0.026)$ \\
\hline \multirow[t]{2}{*}{ Constant } & $0.096 * * *$ & $-0.184 *$ & 0.015 & $-0.130 * *$ & 0.010 & $-0.065^{*}$ & 0.030 & -0.119 & $0.185 * *$ & 0.031 \\
\hline & $(0.032)$ & $(0.010)$ & (0.018) & $(0.060)$ & $(0.010)$ & $(0.035)$ & $(0.024)$ & $(0.083)$ & $(0.086)$ & $(0.313)$ \\
\hline Observations & 100 & 100 & 100 & 100 & 100 & 100 & 100 & 100 & 100 & 100 \\
\hline
\end{tabular}

Notes: Robust standard erro0rs clustered are in brackets; all columns are estimated with a Tobit model. All columns control for province-year fixed effects.

* Statistical significance at $10 \%$ level.

**Statistical significance at $5 \%$ level.

***Statistical significance at $1 \%$ level. 


\subsubsection{Results for Different Information Channel}

Table 4 reports the difference in the impact of average age on polarization index through traditional media (TV) and social media (network). With the one-year increase in average age, each $1 \%$ increase in traditional media penetration rises the Theil index by 0.004 , while each $1 \%$ increase in social media penetration only increases the Theil index by 0.003 . And There is the same trend with the regression coefficients of the other five polarization indicators. Generally speaking, the influence of traditional media on the public view of social events is much greater than that of social media by age.

\subsubsection{Results for Parental Influence}

Table 5 reports the impact of polarization indicators of parents on children at different ages. For children aged between 16 and 39, the polarization index of the parent significantly increases the index of the child and mother's influence is greater than that of the father. For every unit increase of the father's index, the child's indicator increases by 0.291 , while there is a slight increase about 0.302 of mother's effect. For middle-aged people aged between 40 and 64, parents' cognitive indicators do not have a significant impact on their children. The father's polarization index significantly increases the index for people over $65+$ years old, but it has an insignificant impact for mother's indicator. Generally speaking, young people are more influenced by their parents, but the parents of young people are most in the middle age with lower polarization index. So the polarization index of young people is less than that of middle-aged people and the elderly, and the overall index shows an increasing trend with age.

\subsubsection{Results for Different Business Group}

Table 6 reports the regression results of the average age on the five types of public event polarization index by six industries. It can be seen from the table that the average age in the teaching and financial industry does not have a significant correlation with the polarization index, while in the administrative industry, medical industry, self-employed and the unemployed, the polarization index is significantly expanded. And the coefficient of the unemployed is the largest figure among six industries, for about 0.0174 , followed by the self-employed and the pharmaceutical industry, which are 0.0153 and 0.0148 , respectively. The above results are consistent with the previous analysis that in the teaching and financial industries with small Gini coefficients, the public opinions are the most concentrated and do not change significantly with age. But in the case of self-employed and unemployed personnel with more decentralized production activities and non-uniform valuable norms, public views further diverge with age.

\section{Conclusion}

Using data from the four waves of China Family Panel Study, this paper examines the causal effects of the population aging on political polarization in China. We document robust evidence that polarization index of public events is larger for the oldest than for the youngest group in overall and eight measures.

Most importantly, this paper first explains this phenomenon by focusing on the demographic differences in information channel, parental influence, occupation distribution and regional migration between young and old people as evidence of higher polarization. Specifically, the elderly mainly understands the political information through television, while the young usually disseminates information through the Internet. The information segmentation effect of traditional channels promotes the polarization index of the elderly to be greater than that of the young people.

Given that the public polarization indicators continue to increase with age. The parents of young people are mainly in the middle age, while the parents of middle-aged people are mainly in the old age. Therefore, under the influence of parents, the polarization index of young people is smaller than that of middle-aged and older people.

The migration frequency of individuals shows a significant downward trend with age. Due to factors such as employment and school attendance, young people move between multiple provinces for a short period of time, and it is difficult for them to be affected the long-term influence of regional characteristics on individual perceptions. Because of decentralization characteristics between provinces, the Gini coefficient of middle-aged and elderly people has further increased.

Under appropriate assumptions and current situation, these facts can be shown to understand how public views change with the coming of aging society.

\section{Funding}

The work was partially funded by Beijing Municipal Social Science Foundation (No. 17JDYJA021), the Social Science Foundation of Chinese Ministry of Education (No. 18JZD029) and the post-funded projects of the National Social Science Fund (No. 18FJL013).

\section{Conflict of Interest}

The author declares that he has no conflict of interest. 


\section{Appendix}

Table 3. Growth in Polarization 2012 to 2018 of Each Province.

\begin{tabular}{|c|c|c|c|c|c|c|}
\hline & Theil & Gini & Atkinsom (0.5) & Atkinsom (1) & Atkinsom (2) & $\mathbf{N}$ \\
\hline Beijing & 0.039 & 0.150 & 0.021 & 0.045 & 0.109 & 324 \\
\hline Tianjin & 0.037 & 0.142 & 0.021 & 0.047 & 0.145 & 372 \\
\hline Hebei & 0.050 & 0.169 & 0.027 & 0.061 & 0.185 & 4172 \\
\hline Shanxi & 0.046 & 0.164 & 0.025 & 0.054 & 0.158 & 2656 \\
\hline Liaoning & 0.050 & 0.171 & 0.027 & 0.059 & 0.158 & 5960 \\
\hline Jilin & 0.049 & 0.170 & 0.026 & 0.057 & 0.136 & 1072 \\
\hline Hei Longjiang & 0.041 & 0.154 & 0.022 & 0.050 & 0.143 & 1940 \\
\hline Shanghai & 0.040 & 0.156 & 0.021 & 0.045 & 0.106 & 3608 \\
\hline Jiangsu & 0.049 & 0.171 & 0.026 & 0.057 & 0.150 & 1172 \\
\hline Zhejiang & 0.044 & 0.160 & 0.024 & 0.052 & 0.134 & 1120 \\
\hline Anhui & 0.051 & 0.172 & 0.027 & 0.060 & 0.163 & 1184 \\
\hline Fujian & 0.049 & 0.167 & 0.027 & 0.061 & 0.187 & 504 \\
\hline Jiangxi & 0.049 & 0.172 & 0.026 & 0.056 & 0.145 & 980 \\
\hline Shandong & 0.055 & 0.179 & 0.029 & 0.064 & 0.175 & 3236 \\
\hline Henan & 0.044 & 0.160 & 0.024 & 0.053 & 0.155 & 7628 \\
\hline Hubei & 0.041 & 0.157 & 0.022 & 0.046 & 0.117 & 864 \\
\hline Hunan & 0.044 & 0.160 & 0.024 & 0.052 & 0.150 & 1748 \\
\hline Guangdong & 0.037 & 0.147 & 0.020 & 0.043 & 0.117 & 3916 \\
\hline Guangxi & 0.042 & 0.156 & 0.022 & 0.049 & 0.149 & 1012 \\
\hline Chongqing & 0.060 & 0.188 & 0.032 & 0.070 & 0.184 & 448 \\
\hline Sichuan & 0.045 & 0.162 & 0.024 & 0.052 & 0.128 & 2620 \\
\hline Guizhou & 0.045 & 0.164 & 0.024 & 0.052 & 0.139 & 1020 \\
\hline Yunnan & 0.043 & 0.157 & 0.023 & 0.048 & 0.116 & 1764 \\
\hline Shanxi & 0.050 & 0.171 & 0.027 & 0.058 & 0.148 & 1232 \\
\hline Gansu & 0.051 & 0.173 & 0.028 & 0.061 & 0.159 & 6856 \\
\hline
\end{tabular}

Notes: Table shows the change in each province, and in the index, from 2012 to 2018.

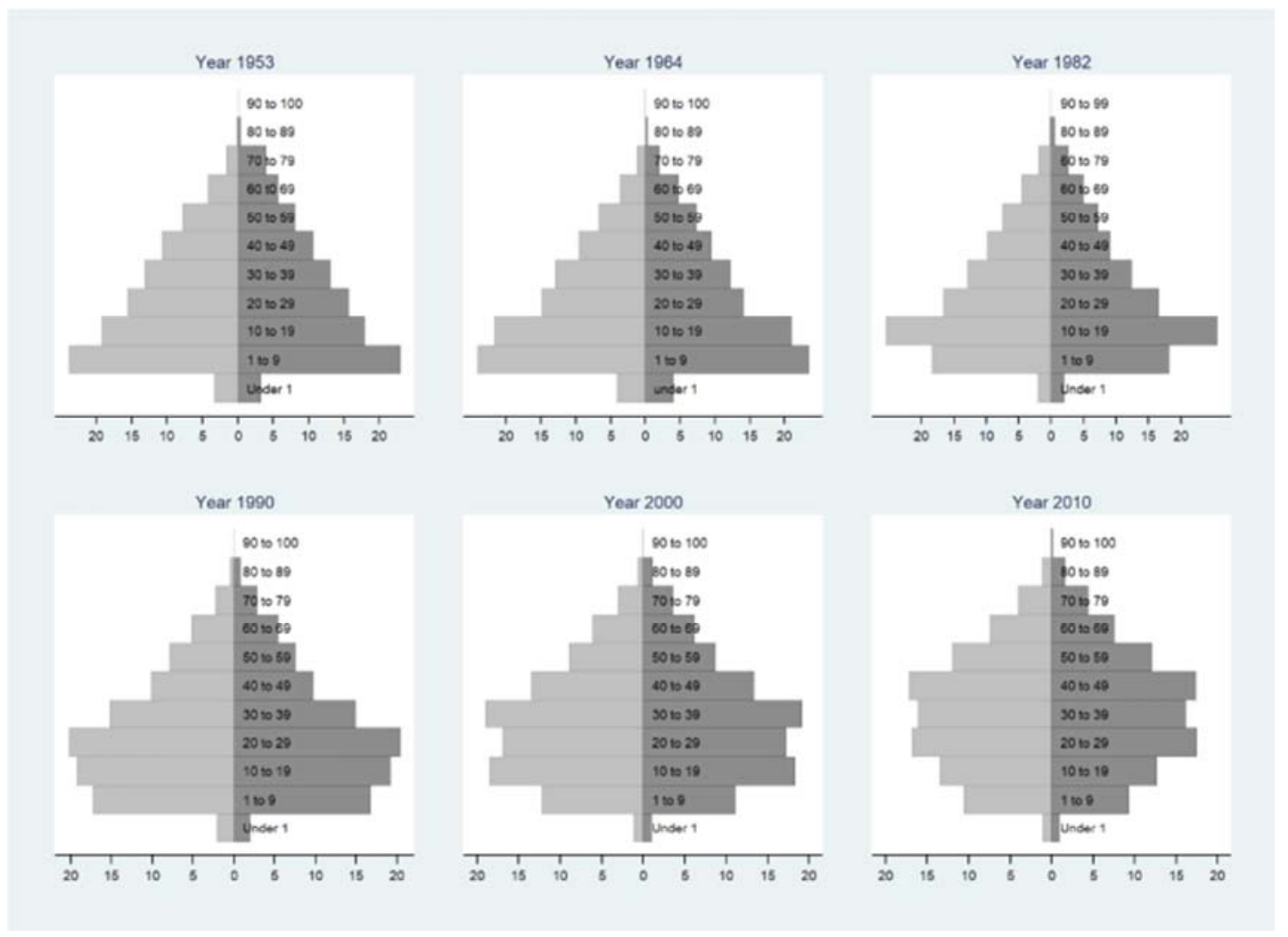

Figure 4. Population Pyramid of Chinese Six Population Censuses.

Source: Chinese population census.

Notes: Each of the six small plots shows the trend of population's age structure across time. The length of the bar chart reflects the proportion of population in each age group. Age is divided into ten stages for every ten years. The light gray represents the male, while the dark gray reflects the characteristics of women. 

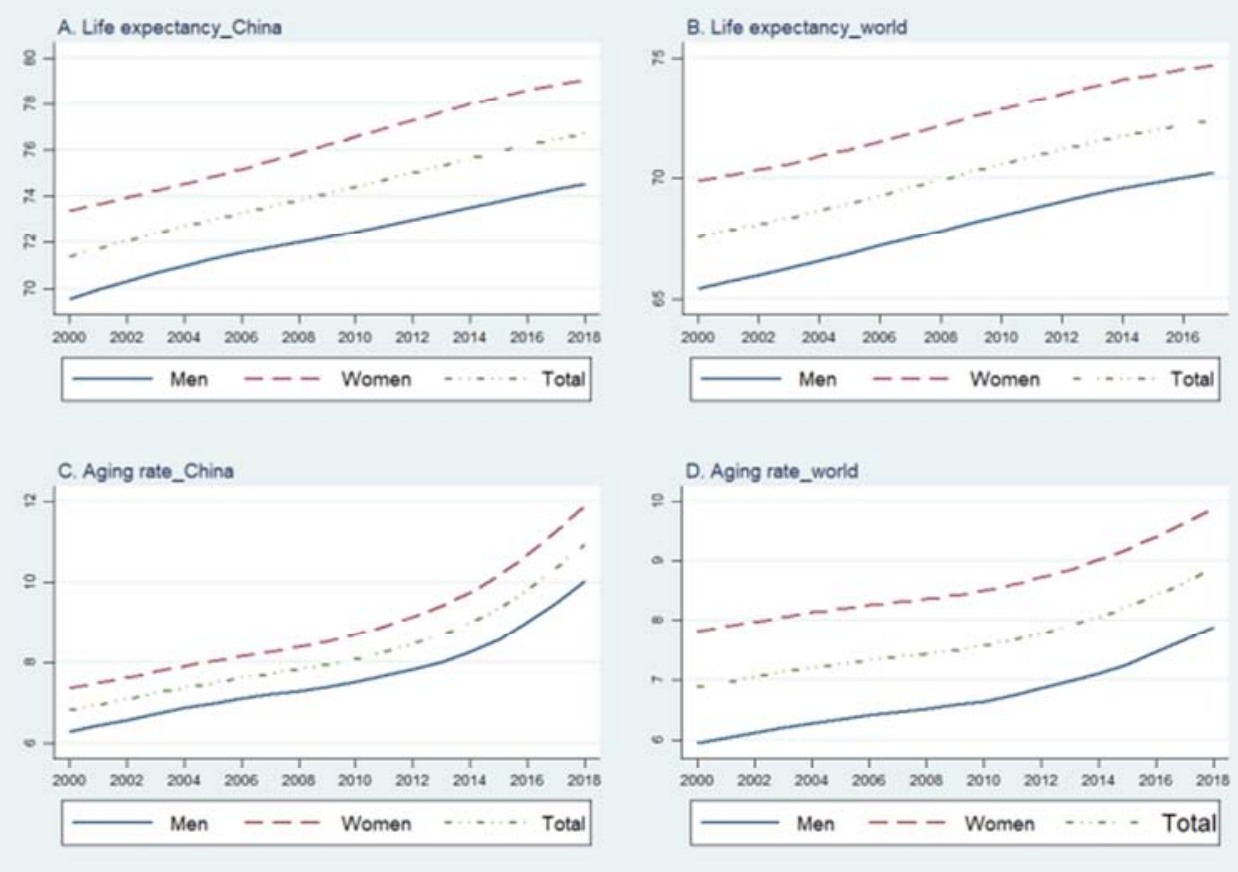

Figure 5. Trends in Life Expectancy and Aging Rate by Gender Group.

Source: WTO (World Trade Organization).

Notes: Panel A shows the average life expectancy in China by gender group. Panel B shows the average life expectancy in the world by gender group. Panel C shows the estimated proportion of the adult Chinese population whose age is over 65 years by gender group. Panel D shows the estimated proportion of the adult population in the world whose age is over 65 years by gender group.
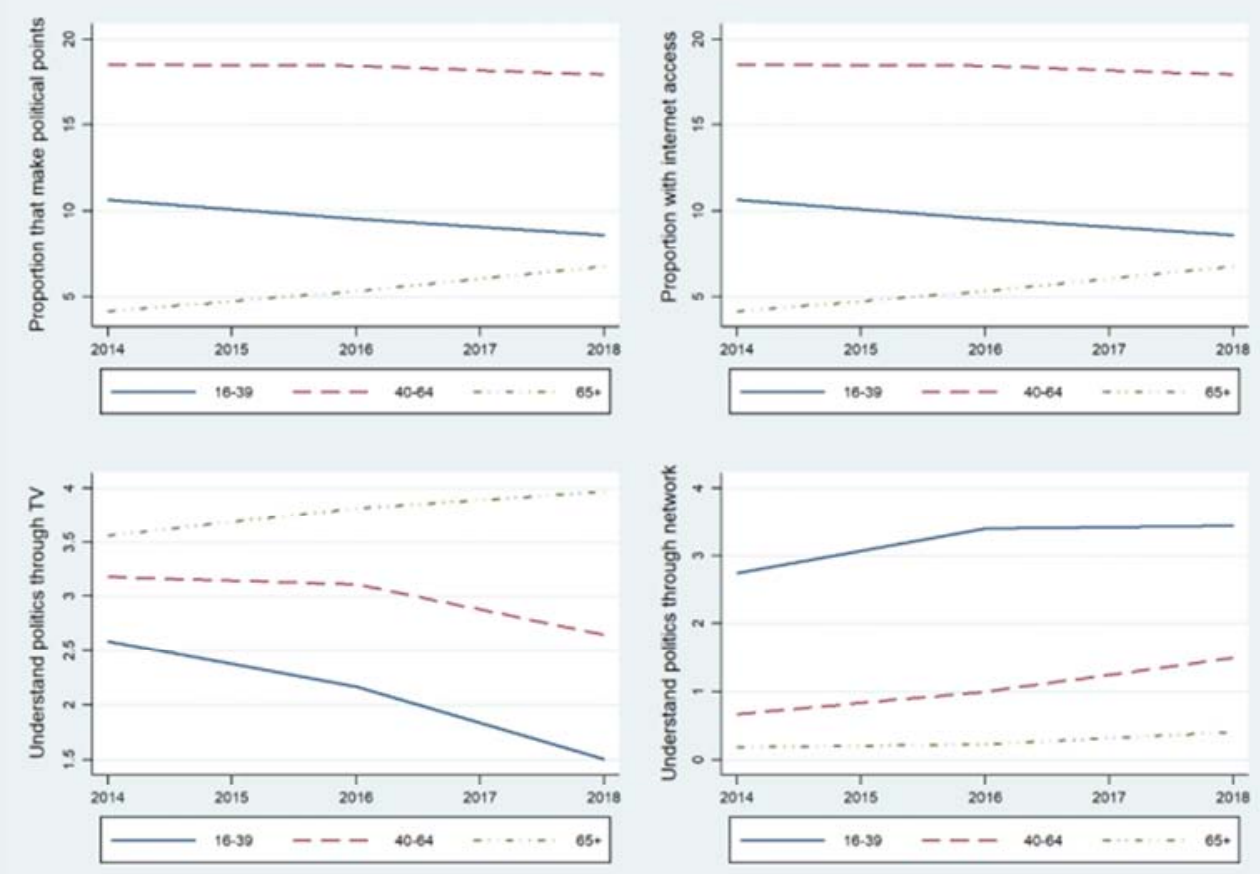

Figure 6. Trends in Public Attention and Information Understanding Channel by Age Group.

Notes: Panel A shows the weighted proportion of respondents who make political speeches through the website by age group. Panel B shows the weighted proportion of respondents who have internet access through mobile phones or computers by age group. Panel C shows the number of days of respondents who learn political information through TV stations by age group. Panel D is the number of days of respondents who learn political information through the Internet by age group. 

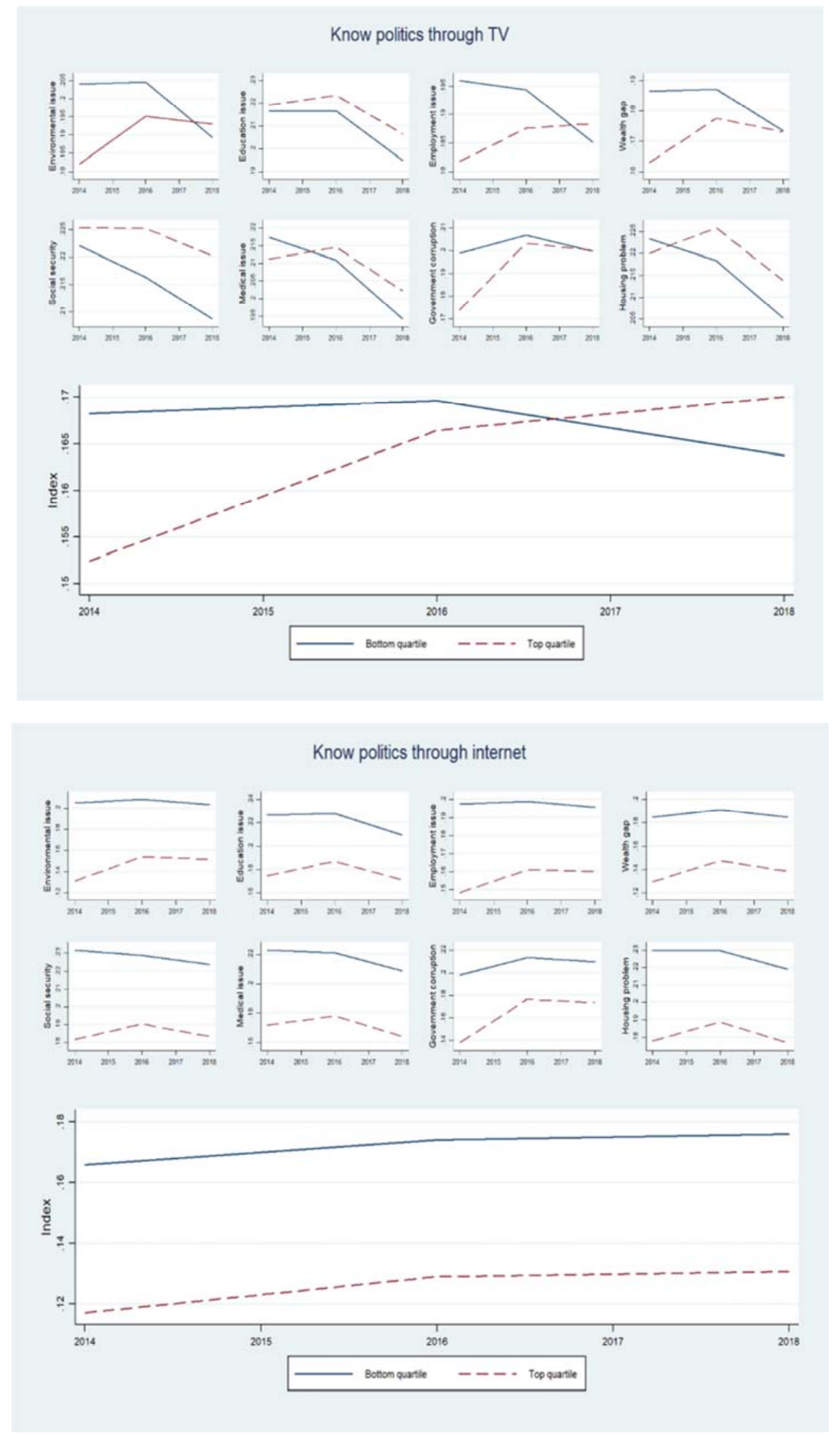

Figure 7. Trends in Polarization by Demographic Group.

Notes: Each plot shows the polarization index broken out by different demographic groups. Panel A shows the index by quartile of public events understanding through TV. Panel B shows the index by quartile of public events understanding through internet. The bottom quartile includes values that less than three days a week, while the top quartile includes values greater than two days a week. For a given measure and group, the polarization value is calculated into Gini coefficient in the full sample. The index is the weighted average of these normalized polarization measures for each group. 

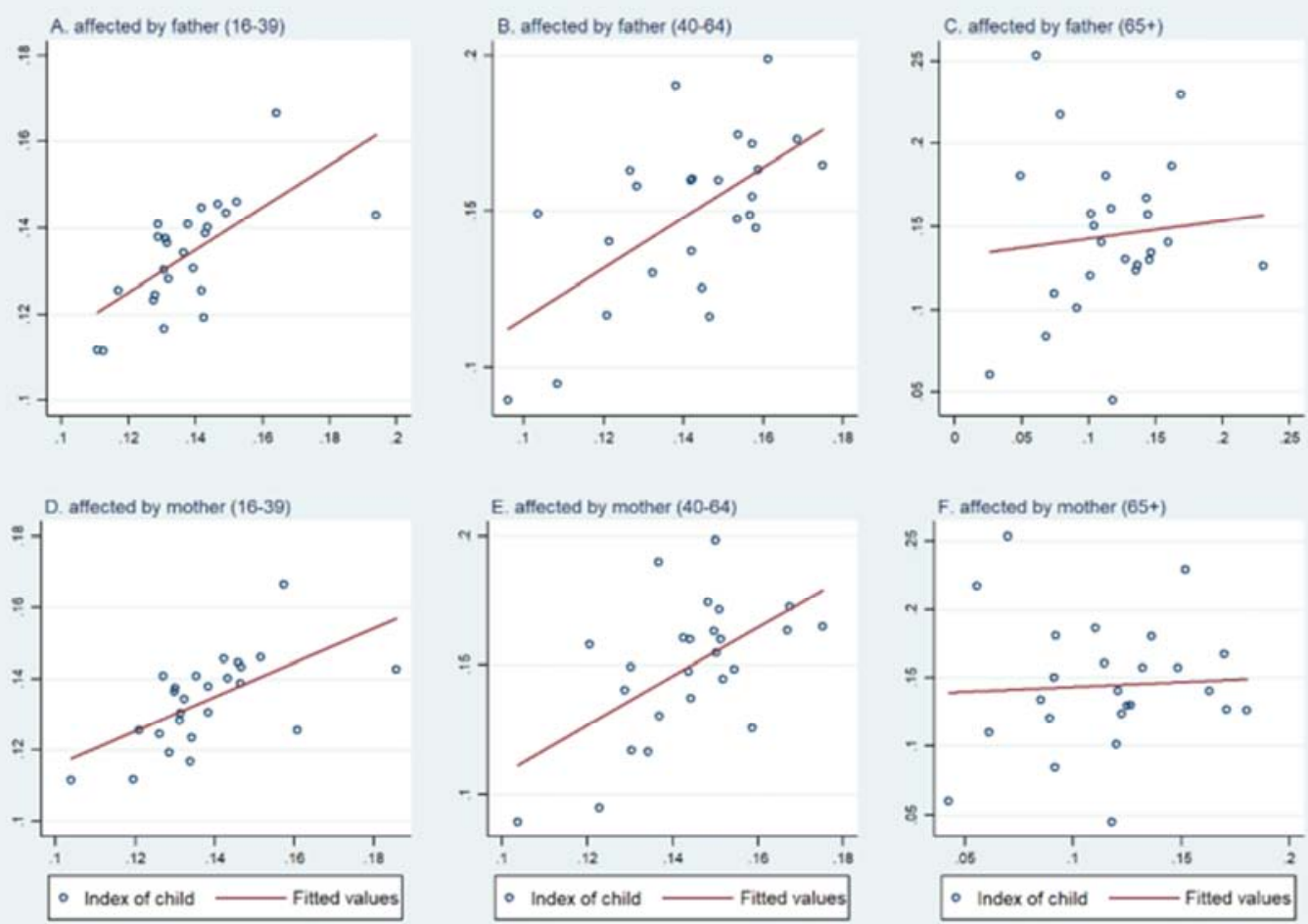

Figure 8. Effect of Parental Index on Child's Index by Age Group.

Notes: The top three plots show the effect of father's index on child's index by age group. The bottom three plots show the effect of mother's index on child's index by age group. The red lines represent the fitted values.
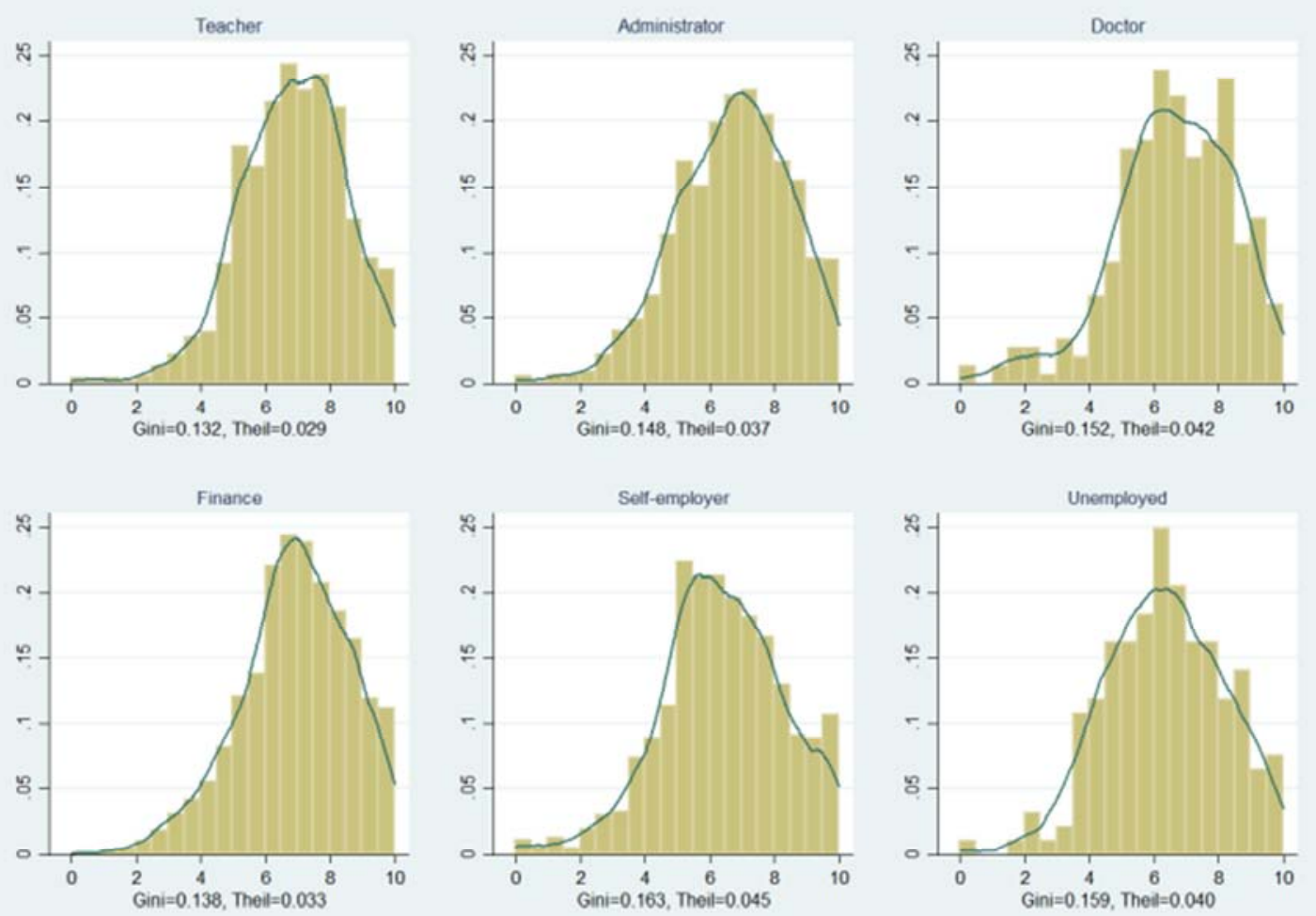

Notes: Each plot shows the distribution characteristics of polarization index by business group. The black line is the kernel density curve.

Figure 9. Frequency Distribution Histogram of Polarization Index by Business Group. 


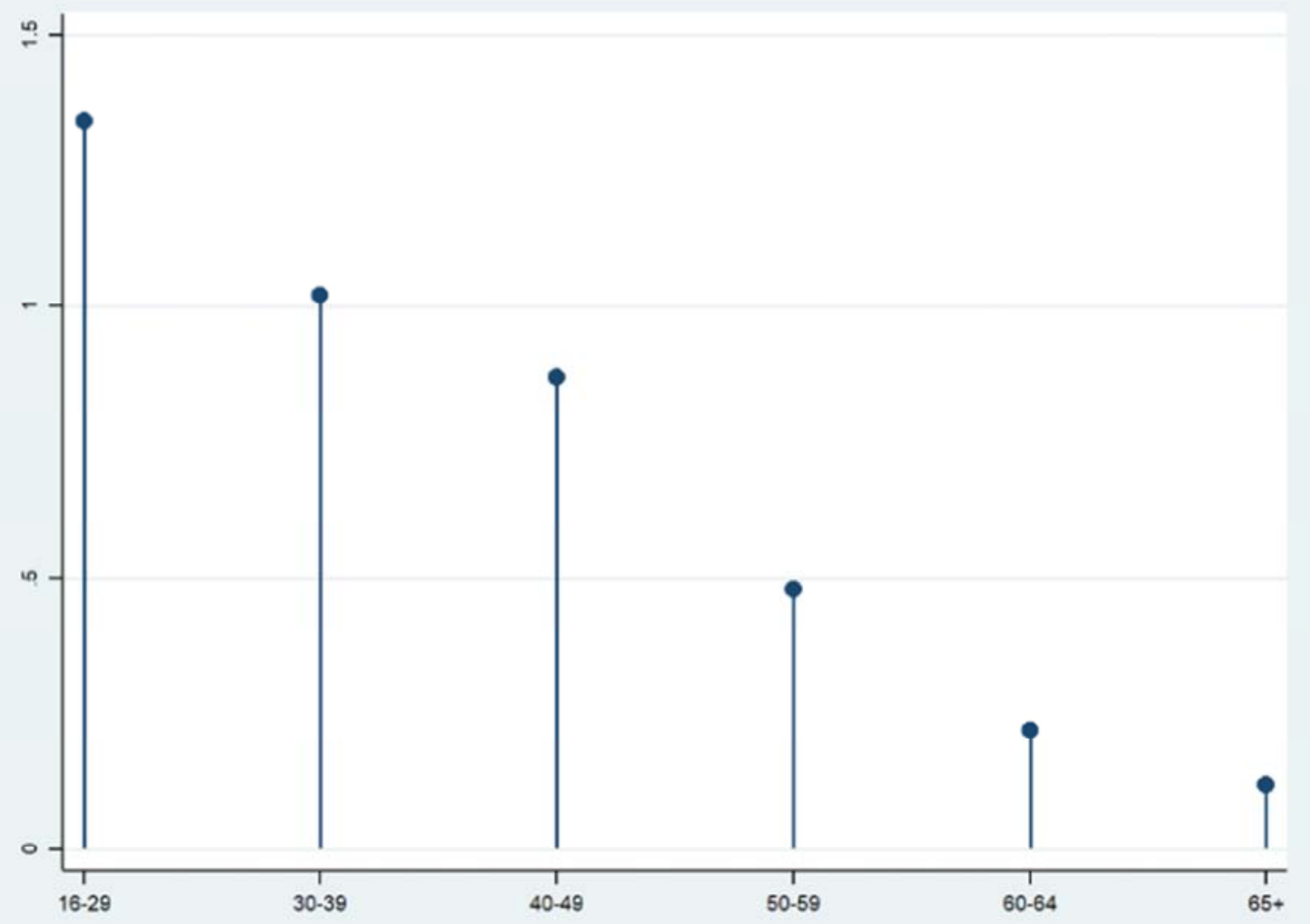

Figure 10. The Frequency of Population Migration by Age Group.

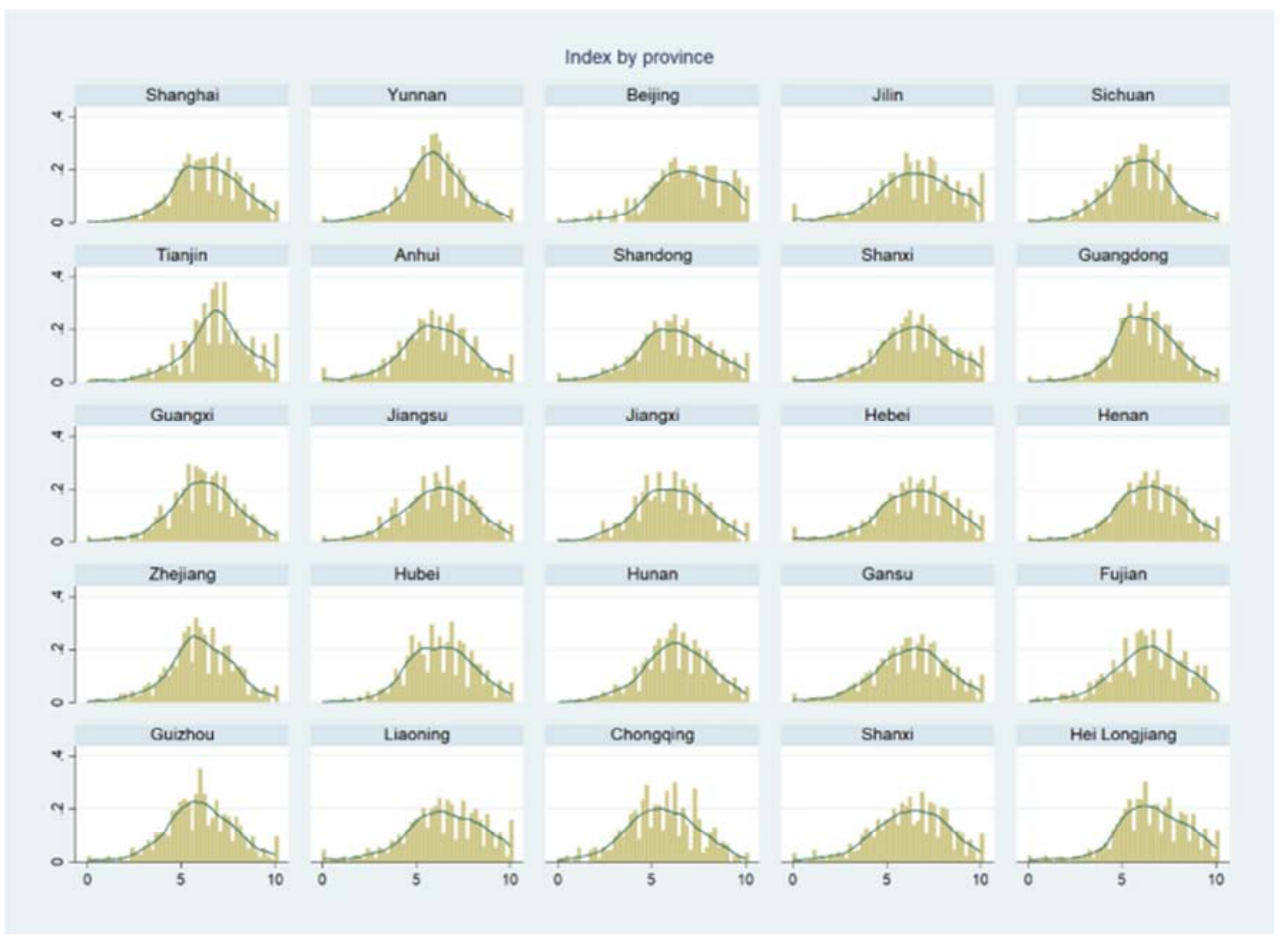

Notes: Each plot shows the distribution characteristics of polarization index by region group. The black line is the kernel density curve.

Figure 11. Frequency Distribution Histogram of Polarization Index by Region Group. 
Table 4. Regression Results for Alternative Measures of Polarization Index by Information Channel.

\begin{tabular}{|c|c|c|c|c|c|c|c|c|c|c|}
\hline & \multirow{2}{*}{$\begin{array}{l}\text { Theil } \\
\text { (1) }\end{array}$} & \multicolumn{3}{|c|}{ Gini } & \multicolumn{2}{|c|}{ Atkinsom (0.5) } & \multicolumn{2}{|c|}{ Atkinsom (1) } & \multicolumn{2}{|c|}{ Atkinsom (2) } \\
\hline & & (2) & (1) & (2) & (1) & (2) & (1) & (2) & (1) & (2) \\
\hline \multirow[t]{2}{*}{ Age*tv } & $0.004 * * *$ & & $0.002 * * *$ & & $0.001 * *$ & & $0.003 * *$ & & 0.003 & \\
\hline & $(0.001)$ & & $(0.001)$ & & $(0.001)$ & & $(0.001)$ & & $(0.005)$ & \\
\hline \multirow[t]{2}{*}{ Age*internet } & & $0.003 * *$ & & $0.002 * *$ & & $0.001 * * *$ & & $0.002 * * *$ & & 0.003 \\
\hline & & $(0.001)$ & & $(0.001)$ & & $(0.0002)$ & & $(0.001)$ & & $(0.003)$ \\
\hline Edu_level & 0.002 & 0.023 & 0.004 & 0.012 & 0.003 & 0.007 & 0.008 & 0.016 & $0.047 *$ & 0.063 \\
\hline \multirow[t]{2}{*}{ lnGDP_per } & 0.004 & 0.041 & -0.001 & 0.016 & -0.001 & 0.007 & -0.006 & 0.013 & -0.048 & 0.044 \\
\hline & $(0.011)$ & $(0.026)$ & $(0.007)$ & $(0.016)$ & $(0.004)$ & $(0.009)$ & $(0.009)$ & $(0.022)$ & $(0.035)$ & $(0.087)$ \\
\hline \multirow[t]{2}{*}{ Urban } & 0.005 & -0.040 & 0.010 & -0.064 & 0.006 & -0.041 & 0.018 & -0.109 & 0.038 & -0.396 \\
\hline & $(0.044)$ & $(0.142)$ & $(0.028)$ & $(0.088)$ & $(0.016)$ & $(0.051)$ & $(0.039)$ & $(0.123)$ & $(0.144)$ & $(0.479)$ \\
\hline \multirow[t]{2}{*}{ Edu_inv } & $0.790 * * *$ & 0.430 & $0.425^{* * *}$ & 0.237 & $0.219 * * *$ & 0.112 & $0.439 * *$ & 0.179 & 0.435 & -0.277 \\
\hline & $(0.235)$ & $(0.437)$ & $(0.146)$ & $(0.269)$ & $(0.085)$ & $(0.155)$ & $(0.206)$ & $(0.377)$ & $(0.763)$ & (1.472) \\
\hline Sec_ins & $(0.067)$ & $(0.161)$ & $(0.042)$ & $(0.099)$ & $(0.024)$ & $(0.057)$ & $(0.059)$ & $(0.139)$ & $(0.217)$ & $(0.541)$ \\
\hline \multirow[t]{2}{*}{ Thi_ins } & -0.021 & 0.001 & -0.019 & 0.006 & -0.011 & 0.010 & -0.025 & 0.039 & -0.011 & 0.183 \\
\hline & $(0.077)$ & $(0.148)$ & $(0.048)$ & $(0.091)$ & $(0.028)$ & $(0.052)$ & $(0.067)$ & $(0.127)$ & $(0.250)$ & $(0.496)$ \\
\hline \multirow[t]{2}{*}{ Trade } & -0.004 & -0.028 & $7.53 e-05$ & -0.012 & 0.0004 & -0.006 & 0.002 & -0.014 & 0.015 & -0.041 \\
\hline & $(0.008)$ & $(0.018)$ & $(0.005)$ & $(0.011)$ & $(0.003)$ & $(0.006)$ & $(0.007)$ & $(0.015)$ & $(0.026)$ & $(0.060)$ \\
\hline \multirow[t]{2}{*}{ Constant } & -0.152 & -0.429 & -0.095 & -0.193 & -0.042 & -0.093 & -0.057 & -0.170 & 0.274 & -0.371 \\
\hline & $(0.113)$ & $(0.293)$ & $(0.070)$ & $(0.180)$ & $(0.041)$ & $(0.104)$ & (0.099) & $(0.253)$ & $(0.368)$ & $(0.987)$ \\
\hline Observations & 100 & & 100 & & 100 & & 100 & & 100 & \\
\hline
\end{tabular}

Notes: Robust standard errors clustered are in brackets; all columns are estimated with a Tobit model. All columns control for province-year fixed effects.

* Statistical significance at $10 \%$ level.

**Statistical significance at $5 \%$ level.

$* * *$ Statistical significance at $1 \%$ level.

Table 5. Regression Results for Alternative Measures of Polarization Index by Parental Influence.

\begin{tabular}{|c|c|c|c|c|c|c|}
\hline & \multicolumn{2}{|l|}{$16-39$} & \multicolumn{2}{|l|}{$40-64$} & \multicolumn{2}{|l|}{$65+$} \\
\hline & (1) & (2) & (3) & (4) & (5) & (6) \\
\hline \multirow[t]{2}{*}{ Mother_gini } & $0.302 * *$ & & 0.041 & & 0.267 & \\
\hline & $(0.146)$ & & $(0.113)$ & & $(0.197)$ & \\
\hline \multirow[t]{2}{*}{ Father_gini } & & $0.291 * *$ & & 0.073 & & $0.286^{*}$ \\
\hline & & $(0.148)$ & & $(0.126)$ & & $(0.166)$ \\
\hline \multirow[t]{2}{*}{ Edu_level } & 0.006 & 0.008 & 0.026 & 0.026 & 0.083 & 0.088 \\
\hline & $(0.038)$ & $(0.038)$ & $(0.056)$ & $(0.055)$ & $(0.117)$ & $(0.115)$ \\
\hline \multirow[t]{2}{*}{ lnGDP_per } & -0.082 & -0.074 & $-0.213 * *$ & $-0.223 * *$ & $0.352^{*}$ & $0.347^{*}$ \\
\hline & $(0.065)$ & $(0.066)$ & $(0.104)$ & $(0.106)$ & $(0.198)$ & $(0.195)$ \\
\hline \multirow[t]{2}{*}{ Urban } & -0.416 & -0.396 & $0.904 *$ & $0.955^{*}$ & -0.379 & -0.014 \\
\hline & $(0.325)$ & $(0.325)$ & $(0.536)$ & $(0.545)$ & (1.169) & (1.138) \\
\hline \multirow[t]{2}{*}{ Edu_inv } & 0.719 & 0.959 & $-3.286^{*}$ & $-3.417^{*}$ & -0.548 & -1.862 \\
\hline & $(1.083)$ & (1.094) & (1.796) & (1.805) & (3.549) & (3.538) \\
\hline Sec_ins & $(0.402)$ & $(0.405)$ & $(0.600)$ & $(0.607)$ & (1.589) & (1.555) \\
\hline \multirow[t]{2}{*}{ Thi_ins } & 0.082 & 0.050 & -0.331 & -0.281 & $-5.374 * * *$ & $-5.201 * * *$ \\
\hline & $(0.371)$ & $(0.373)$ & $(0.550)$ & $(0.558)$ & $(1.785)$ & $(1.747)$ \\
\hline \multirow[t]{2}{*}{ Trade } & 0.065 & 0.065 & $-0.176^{* *}$ & $-0.189 * *$ & 0.302 & 0.256 \\
\hline & $(0.047)$ & $(0.047)$ & $(0.088)$ & $(0.091)$ & $(0.203)$ & $(0.198)$ \\
\hline \multirow[t]{2}{*}{ Constant } & 1.025 & 0.933 & $2.242 * *$ & $2.287 * *$ & 1.144 & 0.818 \\
\hline & $(0.739)$ & $(0.746)$ & (1.121) & (1.123) & $(2.437)$ & $(2.374)$ \\
\hline Observations & 100 & 100 & 98 & 98 & 62 & 63 \\
\hline
\end{tabular}

Notes: Robust standard errors clustered are in brackets; all columns are estimated with a Tobit model. All columns control for province-year fixed effects.

* Statistical significance at $10 \%$ level.

** Statistical significance at 5\% level.

***Statistical significance at $1 \%$ level. 
Table 6. Regression Results for Alternative Measures of Polarization Index by Business Group.

\begin{tabular}{|c|c|c|c|c|c|c|}
\hline & Teacher & Administrator & Finance & Doctor & Self-employer & Unemployed \\
\hline Age & $\begin{array}{l}0.0003 \\
(0.004)\end{array}$ & $\begin{array}{l}0.002 * \\
(0.001)\end{array}$ & $\begin{array}{l}0.001 \\
(0.003)\end{array}$ & $\begin{array}{l}0.015 * * \\
(0.007)\end{array}$ & $\begin{array}{l}0.015 * * \\
(0.006)\end{array}$ & $\begin{array}{l}0.017 * \\
(0.010)\end{array}$ \\
\hline Edu_level & $\begin{array}{l}0.012 \\
(0.030)\end{array}$ & $\begin{array}{l}-0.033 \\
(0.029)\end{array}$ & $\begin{array}{l}-0.036 \\
(0.048)\end{array}$ & $\begin{array}{l}-0.093 * * \\
(0.047)\end{array}$ & $\begin{array}{l}-0.016 \\
(0.027)\end{array}$ & $\begin{array}{l}0.046 \\
(0.099)\end{array}$ \\
\hline lnGDP_per & $\begin{array}{l}-0.0003 \\
(0.036)\end{array}$ & $\begin{array}{l}0.029 \\
(0.037)\end{array}$ & $\begin{array}{l}-0.197 * * * \\
(0.072)\end{array}$ & $\begin{array}{l}-0.051 \\
(0.059)\end{array}$ & $\begin{array}{l}0.034 \\
(0.032)\end{array}$ & $\begin{array}{l}-0.085 \\
(0.172)\end{array}$ \\
\hline Urban & $\begin{array}{l}0.052 \\
(0.165)\end{array}$ & $\begin{array}{l}-0.247 \\
(0.177)\end{array}$ & $\begin{array}{l}1.042 * * \\
(0.427)\end{array}$ & $\begin{array}{l}0.298 \\
(0.300)\end{array}$ & $\begin{array}{l}-0.059 \\
(0.143)\end{array}$ & $\begin{array}{l}0.559 \\
(1.039)\end{array}$ \\
\hline Edu_inv & $\begin{array}{l}-0.375 \\
(0.789)\end{array}$ & $\begin{array}{l}-1.319 * \\
(0.745)\end{array}$ & $\begin{array}{l}-0.608 \\
(1.338)\end{array}$ & $\begin{array}{l}0.924 \\
(1.289)\end{array}$ & $\begin{array}{l}0.163 \\
(0.672)\end{array}$ & $\begin{array}{l}-1.983 \\
(3.220)\end{array}$ \\
\hline Sec_ins & $\begin{array}{l}0.136 \\
(0.235)\end{array}$ & $\begin{array}{l}0.005 \\
(0.268)\end{array}$ & $\begin{array}{l}0.417 \\
(0.480)\end{array}$ & $\begin{array}{l}0.809 \\
(0.573)\end{array}$ & $\begin{array}{l}-0.009 \\
(0.204)\end{array}$ & $\begin{array}{l}1.362 \\
(1.472)\end{array}$ \\
\hline Thi_ins & $\begin{array}{l}0.140 \\
(0.268)\end{array}$ & $\begin{array}{l}0.134 \\
(0.284)\end{array}$ & $\begin{array}{l}0.203 \\
(0.456)\end{array}$ & $\begin{array}{l}0.585 \\
(0.527)\end{array}$ & $\begin{array}{l}0.009 \\
(0.229)\end{array}$ & $\begin{array}{l}1.132 \\
(1.679)\end{array}$ \\
\hline Trade & $\begin{array}{l}-0.073 * * \\
(0.029)\end{array}$ & $\begin{array}{l}-0.008 \\
(0.028)\end{array}$ & $\begin{array}{l}-0.181 * * \\
(0.073)\end{array}$ & $\begin{array}{l}-0.147 * * * \\
(0.051)\end{array}$ & $\begin{array}{l}-0.010 \\
(0.026)\end{array}$ & $\begin{array}{l}-0.379 * * \\
(0.184)\end{array}$ \\
\hline Observations & 84 & 96 & 98 & 63 & 96 & 46 \\
\hline
\end{tabular}

Notes: Robust standard errors clustered are in brackets; all columns are estimated with a Tobit model. All columns control for province-year fixed effects.

* Statistical significance at $10 \%$ level.

**Statistical significance at 5\% level.

***Statistical significance at $1 \%$ level.

\section{References}

[1] Boxell, L., Gentzkow, M., \& Shapiro, J. M. (2017). Greater internet use is not associated with faster growth in political polarization among US demographic groups. Proceedings of the National Academy of Sciences-PNAS, 114 (40), 10612-10617.

[2] Choi, K., \& Shin, S. (2015). Population aging, economic growth, and the social transmission of human capital: An analysis with an overlapping generations model. Economic Modelling, 50, 138-147.

[3] Christensen, K., Prof, Doblhammer, G., Prof, Rau, R., PhD, \& Vaupel, J. W., Prof. (2009). Ageing populations: The challenges ahead. The Lancet (British Edition), 374 (9696), 1196-1208.

[4] Dall, T. M., Gallo, P. D., Chakrabarti, R., West, T., Semilla, A. P., \& Storm, M. V. (2013). An aging population and growing disease burden will require a large and specialized health care workforce by 2025. Health Affairs (Project Hope), 32 (11), 2013-2020.

[5] Gurwitz, J. H., \& Pearson, S. D. (2019). Novel therapies for an aging population: Grappling with price, value, and affordability. JAMA: The Journal of the American Medical Association, 321 (16), 1567-1568.

[6] Jivraj S, Nazroo J, Barnes M. Change in social detachment in older age in England. In: Banks J, Nazroo J, Steptoe A, eds. The Dynamics of Ageing: Evidence From the English Longitudinal Study of Ageing 2002-10 (Wave 5). London, UK: Institute for Fiscal Studies, 2012.

[7] Kendig, H., Browning, C. J., Thomas, S. A., \& Wells, Y. (2014). Health, lifestyle, and gender influences on aging well: An australian longitudinal analysis to guide health promotion. Frontiers in Public Health, 2, 70-70.
[8] Kingston, A., Robinson, L., Booth, H., Knapp, M., Jagger, C., MODEM Project, MODEM project, \& for the MODEM project. (2018). Projections of multi-morbidity in the older population in england to 2035: Estimates from the population ageing and care simulation (PACSim) model. Age and Ageing, 47 (3), 374-380.

[9] Li, G., Li, Z., \& Lv, X. (2021). The ageing population, dependency burdens and household commercial insurance purchase: Evidence from china. Applied Economics Letters, 28 (4), 294-298.

[10] Liang, Y., Niu, X., \& Lu, P. (2020). The aging population in china: Subjective well-being of empty nesters in rural eastern china. Journal of Health PsyFigure 1. Trends in Polarization of Public Events

[11] Sabater, A., Graham, E., \& Finney, N. (2017). The spatialities of ageing: Evidencing increasing spatial polarisation between older and younger adults in england and wales. Demographic Research, 36 (1), 731-744.

[12] Sander, M., Oxlund, B., Jespersen, A., Krasnik, A., Mortensen, E. L., Westendorp, R. G. J., \& Rasmussen, L. J. (2015). The challenges of human population ageing. Age and Ageing, 44 (2), 185-187.

[13] Shen, Y., Han, W., Yu, X., Liu, Z., Jiang, J., \& Zhang, S. (2018). Predicting blood supply and demand in the next 20 years with population ageing in china: A cross-sectional study. The Lancet (British Edition), 392, S62.

[14] Spijker, J., \& MacInnes, J. (2013). Population ageing: The timebomb that isn't? British Medical Journal, 347 (7933), 20-22.

[15] Zhong, H. (2011). The impact of population aging on income inequality in developing countries: Evidence from rural china. China Economic Review, 22 (1), 98-107. 